\title{
Experimental and Numerical Investigations of Dyke Failures Involving Soft Materials
}

\author{
Elliot James Fern · Dirk Arie de Lange · Cor Zwanenburg · Johannes Antonius \\ Maria Teunissen · Alexander Rohe · Kenichi Soga
}

Received: date / Accepted: date

Abstract This paper presents the results of an experimenta and numerical investigation on the collapse of dykes involving soft soils. Nine centrifuge tests were carried out to investigate the dyke-subsoil interaction. The tests consisted in placing a dyke made out of Speswhite clay or Baskarp sand on a subsoil. The dykes and the subsoils were alternatively changed to explore the different contrast in stiffness ranging from stiff dykes on soft subsoil to soft dykes on stiff subsoils. The small scale models were placed in the centrifuge and were progressively accelerated up to a maximum of 100 G. The video recordings, which were then processed by Particle Image Velocimetry (PIV), offered an insight onto the deformation and failure mechanisms. The results showed that dykes placed on a stiff subsoil underwent brittle failures with the development of slip surfaces whereas the same dyke placed on a soft subsoil underwent large deformation

E. J. Fern and K. Soga

University of Cambridge

Department of Engineering

Trumpington Street

Cambridge

CB2 1PZ

United Kingdom

E-mail: jf497@cam.ac.uk

D. de Lange, C. Zwanenburg, J.A.M. Teunissen and A. Rohe Deltares

Geo-Engineering

Boussinesqweg 1

2611 HD Delft

The Netherlands

E-mail: dirk.delange@deltares.nl which presented a serviceability issue. These tests were then modelled with the Material Point Method (MPM), which is a continuum-based method for numerical simulation dedicated for large deformation problems. Simple constitutive models were used for which the parameters could be estimated using state indices.

Keywords Dyke - Levee - Soft soils - Slope failure · Centrifuge testing $\cdot$ Material point method

\section{Introduction}

The rapid expansion of urban areas and the rise of sea levels associated with the subsidence of land are putting ever increasing economical and social pressures on the flood defence systems of urban deltas (Seed, 2007). The lowlands of the Netherlands is home to more than 50\% of its population and economical activity which includes the regions of Amsterdam, the Hague and Rotterdam. These areas are protected against flooding by an extensive network of dykes for which the design requirements are extremely high; the design return period is 10,000 years. However, a number failures took place in the past two decades. The Bleiswijk dyke, located near Rotterdam, failed in August 1990 (Vink, 1994). In 2003, the Wilnis dyke, located near Amsterdam, collapsed causing no casualties but extensive damage to property (i.e. Van Baars, 2005). These failures are not specific to the Netherlands. The United States has also experienced failures of dykes and levees. In 2005, Hurricane Katrina caused 42 
many dykes, levees and flood barriers to fail in the vicinity of New Orleans, Louisiana. The failures were attributed to a lack of assessment of the mechanical properties of the subsoil outside the footprint of the levee and unforeseen failure mechanisms, among other reasons (Andersen et al., 2007; Sills et al., 2008). Following this event, the US Army Corps of Engineers assessed the stability of their dykes and found nearly 150 which posed unacceptable risk of failure during major flood episodes (Abdoun et al., 2010). The Dutch authorities carried out a similar investigation and identified some dykes as being critical (i.e. Markermeer). However, the long history of these dykes and the reduction in loads, due to the construction of a closure dams and flood barriers, raise the question of how the stability of these dykes should be addressed and this requires a thorough understanding of the failure mechanisms. However, the failure of a dyke is complex and can involve several mechanisms, which are not always fully understood; Koelewijn et al. (2004), Zwanenburg et al. (2012) and Van Baars (2005) give a description of three different failure mechanism, respectively.

Following the Wilnis dyke failure, a number of experimental programmes were carried out in the Netherlands (i.e. Koelewijn and Van, 2002). Among them was the IJkdijk project (i.e. Zwanenburg et al., 2012) and consisted of a fullscale dyke subjected to an increase in pore pressure which caused the failure. The results showed that the soft layers of soil influenced the failure mechanism. Large scale tests mobilise a lot of human, technical and financial resources and could only be carried out in small numbers. Centrifuge testing offered an alternative with which it was possible to carry out more tests within a short period of time and at a smaller cost. Preliminary studies were carried out to investigate the feasibility of testing dyke failures in the centrifuge (Van et al., 2009) and were used as a basis for the tests presented in this paper. The loading paths of a dyke leading to failure are experimentally difficult to reproduce and control (i.e. groundwater seepage, piping, etc.). Thus, a simpler loading path was favoured, though not realistic, but could be fully controlled during the experiment - gravity loading.

In this study, nine centrifuge tests were carried out and consisted of dykes made out of Speswhite clay or Baskarp sand and placed on a subsoil. The dyke and the subsoil were alternatively changed to explore different contrast in stiffness ranging from stiff dykes on soft subsoil to soft dykes on stiff subsoils. The small scale models were placed in the centrifuge and were progressively accelerated up to a maximum of $100 \mathrm{G}$ depending on when the failure occurred. This loading path differed from those observed in the field. However, it offered simplicity in execution and understanding for a first testing programme. Numerical modelling and analysis were then carried out using the Material Point Method (MPM) (Sulsky et al., 1994, 1995) in order to investigate the feasibility of MPM to capture the observed failures and gain additional insight on the failure mechanisms.

\section{Description of Centrifuge Tests}

The centrifuge tests were carried out at Deltares (formerly Geo-Delft), the Netherlands, with their geotechnical centrifuge (Fig. 1). It is a $300 \mathrm{G}$-force beam centrifuge with an arm length of $5.5 \mathrm{~m}$.

The tests consisted in modelling the failure of dykes resting on different subsoils. Six tests consisted of clayey dykes made out of Speswhite clay and resting on a silicon subsoils which were used to replicate the large deformation capacity of soft soils such as peat, which are difficult to model in the centrifuge due to their fibrous nature. However, the silicon can only reproduce the stiffness of the soft material and not the elasto-plastic behaviour of real soil. The stiffness of silicon can be controlled during preparation and three silicon blocks were built with, respectively, three different stiffnesses which mimicked different soft soils. Three additional tests were carried out and consisted of dykes made out of Baskarp sand. One consisted of a sandy dyke resting on a soft silicon subsoil and two tests consisted of a sandy dyke resting on a remoulded, natural and soft clay called Oostvaardersplassen (OVP) clay (Hjortneas-Pedersen and Broers, 1993). These two tests were identical but showed different failure patterns due to the natural imperfection in the OVP clay. Table 1 summarizes the test programme.

All models were built in a plane strain configuration inside a rectangular strong box with a glass face. The dimensions of the dyke and the thickness of the subsoil changed between tests with a silicon subsoil (Model 1) and those with the OVP clay subsoil (Model 2). The latter was smaller 


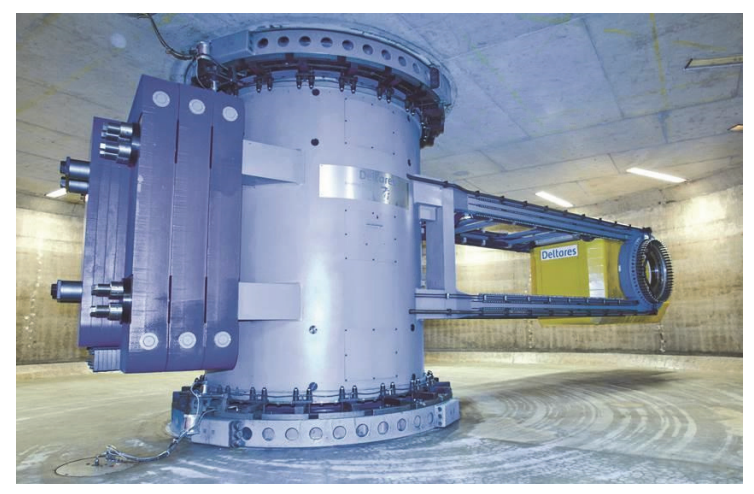

Fig. 1 The beam centrifuge at Deltares, the Netherlands.

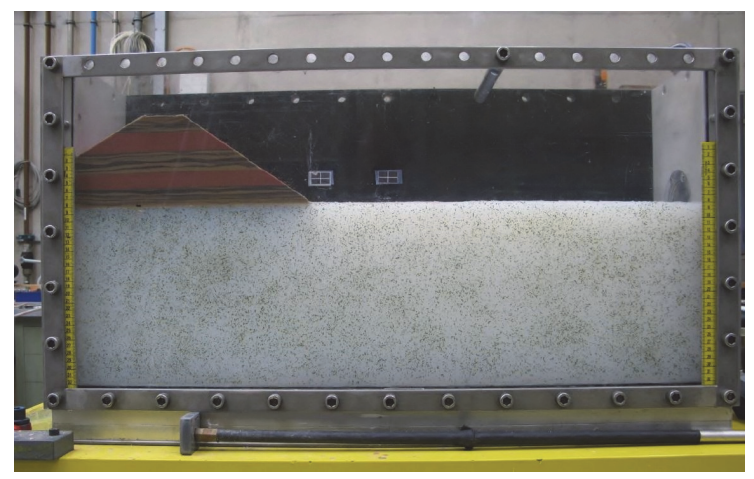

Fig. 2 Model 1 with a stiff sandy dyke and a soft silicon subsoil (Test I).

Table 1 Centrifuge test programme.

\begin{tabular}{|c|l|l|c|}
\hline Test & Dyke & Subsoil & Model \\
\hline \hline A & Med.-Stiff SW clay & Stiff silicon & 1 \\
\hline B & Med.-Stiff SW clay & Med.-stiff silicon & 1 \\
\hline C & Med.-Stiff SW clay & Soft silicon & 1 \\
\hline \hline D & Soft SW clay & Stiff silicon & 1 \\
\hline \hline E & Stiff SW clay & Stiff silicon & 1 \\
\hline F & Stiff SW clay & Soft silicon & 1 \\
\hline \hline G & Dense B sand & Soft OVP clay & 2 \\
\hline H & Dense B sand & Soft OVP clay & 2 \\
\hline I & Dense B sand & Soft silicon & 1 \\
\hline
\end{tabular}

where SW stands for Speswhite, B for Baskarp and OVP for Oostvaardersplassen. in order to reduce the consolidation time due to time constraints of the project. The dyke and the subsoil were made out of, respectively, one material. In other words, the dyke was made entirely out Speswhite clay or Baskarp sand and the subsoil entirely out of silicon or OVP clay. The dyke had an asymmetric geometry with one steep slope (1:1.5) and shallower slope (1:2). The dyke was truncated in order to

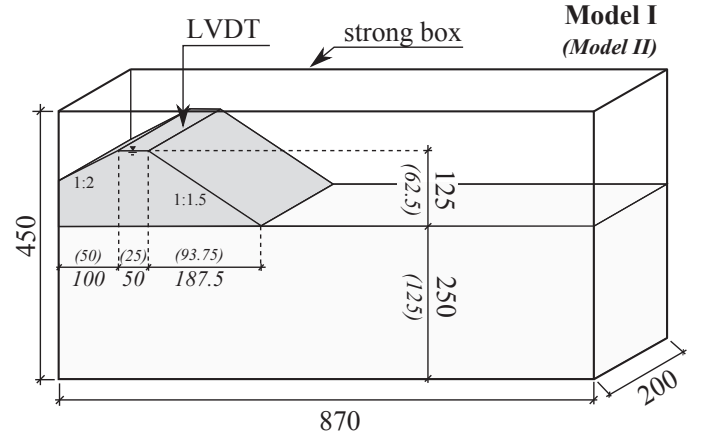

Fig. 3 Centrifuge model: Model 1 for Test A-F and I and Model 2 for Test $\mathrm{G}$ and $\mathrm{H}$. Dimensions are in millimetres.

force the failure in one direction. Fig. 2 shows a photograph $\quad{ }_{133}$ of the centrifuge model and Fig. 3 gives the dimensions.

The models were subjected to an increase in gravity from 1 to $100 \mathrm{G}$ with a rate of $1 \mathrm{G} / \mathrm{min}$. For operational reasons, a vacuum was created in the centrifuge chamber in order to reduce the drag force. This was carried out at $20 \mathrm{G}$ for the clayey dykes and at 40 or $50 \mathrm{G}$ for the sandy dykes. During this phase, the G-level was maintained constant but displacements of the crown were still observed and will be discussed in a later section (Fig. 7). No other loads were applied to the model.

\subsection{Model Preparation and Instrumentation}

The clayey dykes were made out of Speswhite clay which is a fined grained kaolin with a low permeability $\left(K_{\text {sat }}=10^{-9}\right.$ $\mathrm{m} / \mathrm{s}$ ), a liquid limit of $69 \%$ and a plastic limit of $38 \%$. It was prepared in a stiff tub and consolidated with a vertical pressure $\sigma_{v, c}^{\prime}$ of 50,100 or $150 \mathrm{kPa}$. It was then extracted from the tub, cut into a block and placed in the strong box on the silicon block. The faces of the strong box were smeared with Vaseline in order to reduce the friction between the model and the strong box. The contact between the dyke and the subsoil was carefully prepared in order to obtain a intimate contact between them. Once the block was in place, the Speswhite clay was trimmed into a dyke. Speckles were then blown on the face of the dyke in order to allow the Particle Image Velocimetry (PIV) analysis (White et al., 2003). The front and the rear panels of the strong box were mounted 
and the container was sealed until the test was carried out the next day.

The sandy dykes were made out of Baskarp sand which is a uniformly graded silica sand with a dominant grain size of $0.1 \mathrm{~mm}$. It has a critical state friction angle $\varphi_{c s}^{\prime}$ of $32^{\circ}$, a minimum void ratio $e_{\min }$ of 0.65 , a maximum void ratio $e_{\max }$ of 0.96 and a specific gravity $G_{s}$ of 2.65. The silicon block was first placed in the strong box and the sides of the strong box mounted. Then, the sand was placed and tamped under water to achieve a relative density of $90 \%$. Different layers of sand were coloured in order to facilitate the visualisation of the deformation. The sand was then drained and trimmed to the shape of the desired dyke. The strong box was then covered and the test took place the next day.

The silicon subsoil was prepared in the form of blocks and to achieve a specific stiffness. A specific block was chosen according to its stiffness and placed in the strong box. The dyke was then built on it. The mechanical behaviour of silicon is complex (e.g. viscosity). However, the assumed influence of the time dependent behaviour of silicon was limited by the short duration of the test (100 minutes). It was supposed that the silicon was elastic and incompressible with a Poisson ratio of $v=0.5$. The results of the tests confirmed its ability to recover deformation. The secant elastic Young's modulus $E$ was determined by means of element testing (uniaxial compression tests) and were respectively for the soft, medium-stiff and stiff blocks $114 \mathrm{kPa}, 565 \mathrm{kPa}$ and $1,377 \mathrm{kPa}$.

The clayey subsoils were made out of OVP clay which is a natural and soft silty clay and was remoulded in a tub and subjected to a preconsolidation pressure of $30 \mathrm{kPa}$. It was then trimmed to the desired dimension and placed in the strong box using a vacuum crane. The block was then trimmed into a dyke. Yellow speckles were then blown on the subsoil to facilitate the PIV analysis.

The deformations of the dyke and the subsoil were tracked by cameras and allowed PIV analysis. A LVDT was mounted to measured the displacement at the crown of the dyke.

\section{Results of The Centrifuge Tests}

Tests A to C consisted of dykes made out of Speswhite clay with a vertical consolidation pressure $\sigma_{v, c}^{\prime}$ of $100 \mathrm{kPa}$ and were placed on a stiff, medium-stiff and soft silicon subsoil, respectively. A vacuum in the centrifuge chamber was applied at $20 \mathrm{G}$ for operational reasons.

Test A consisted of a clayey dyke with an initial water content $w$ of $56 \%$ and an undrained strength $s_{u}$ of $6 \mathrm{kPa}$ measured with a pocket penetrometer during the model preparation. It rested on a stiff silicon block. The model was then accelerated up to a $100 \mathrm{G}$ in a 100 minutes. The results showed very little deformation until $40 \mathrm{G}$ at which point some large deformation took place followed by a brittle failure. A curved failure surface propagated from the base to the crown of the dyke and part of the dyke slid as a block (Fig. 4.A). The PIV analysis showed the development of a thin curved failure surface (Fig. 5.A). The failed dyke then progressively slid along the slip surface until a second failure took place at $80 \mathrm{G}$. Little deformation of the stiff silicon block was observed throughout the test. Fig. 7.A. shows the displacement of the crown as a function of the G-force and in which the failure is clearly visible.

Test B consisted of a clayey dyke with an initial water content $w$ of $55 \%$ and an undrained strength $s_{u}$ of $8 \mathrm{kPa}$. It rested on a medium-stiff silicon subsoil. Unlike for Tes A, The results show that deformation takes place from an early stage. The silicon subsoil had a lower stiffness than for Test A. Therefore, the subsoil underwent larger deformation which induced some progressive deformations in the dyke before two brittle failures took place shortly one after each other at around 48 G. Fig. 4.B shows the final configuration of the model in which the two failure surfaces are clearly visible. The PIV analysis (Fig. 5.B) shows the two slip surfaces. Fig. 7.A shows the displacement of the crown in which the on-set of the double failure can be seen.

Test $\mathrm{C}$ consisted of a clayey dyke with an initial water content $w$ of $55 \%$ and an undrained strength $s_{u}$ of $7 \mathrm{kPa}$. It rested on a soft silicon subsoil. The results show large deformation taking place in the subsoil and resulted in large induced-deformation in the dyke. At around $40 \mathrm{G}$, larger de- 


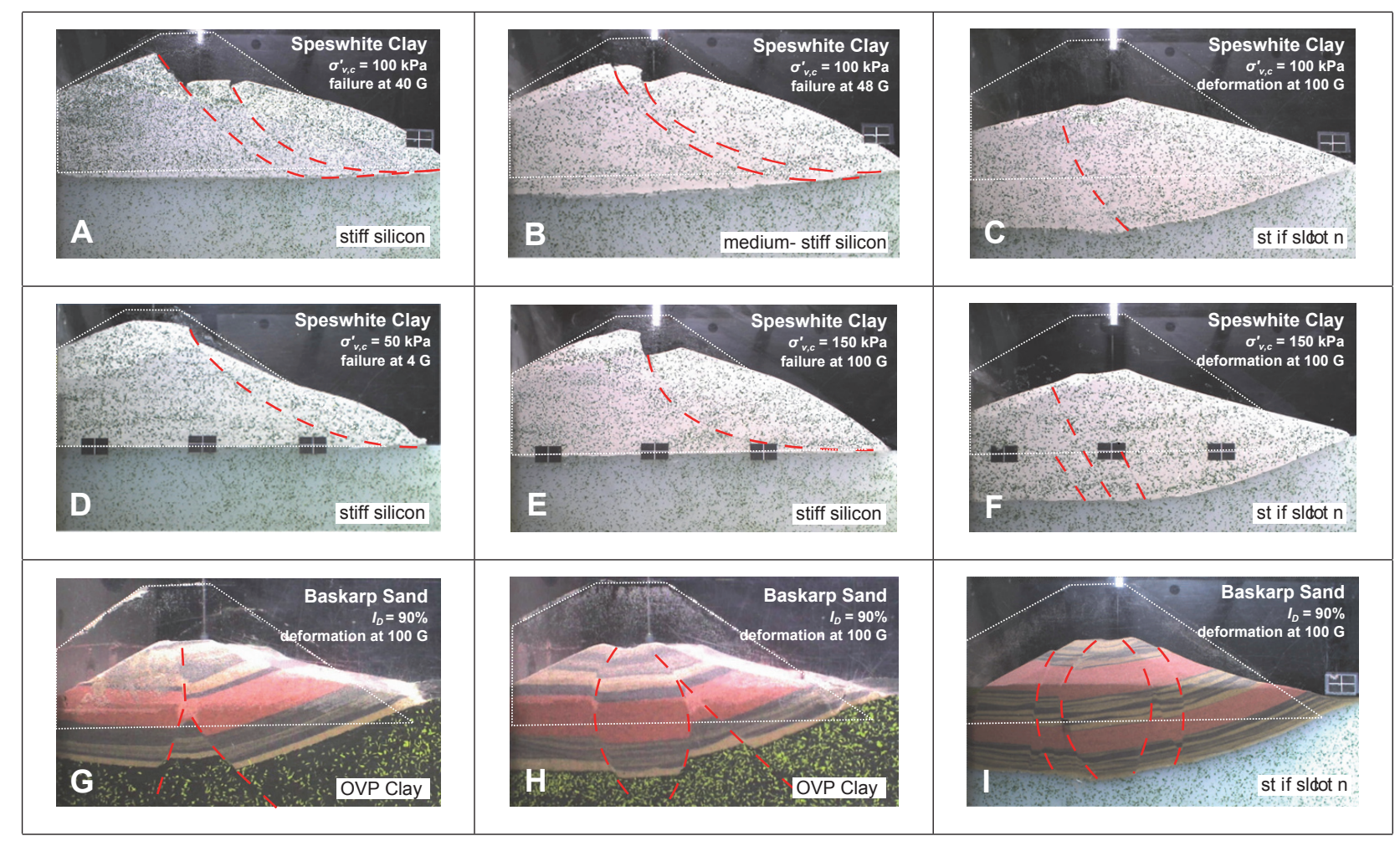

Fig. 4 Results of the nine centrifuge tests. The photographs illustrate the deformed configuration at a $100 \mathrm{G}$ for all tests except for Test D which failed at 4 G. Red dashed lines highlight the localised failures. Sub-figures are hyperlinked to the full video recording of the test.

formation took place within the dyke and over an extensive area of the dyke without any brittle failure taking place. Fig. 4.C shows the final configuration at $100 \mathrm{G}$ in which it can be seen that the deformed subsoil formed a dip in which the dyke sat. The PIV analysis confirmed the existence of a diffused sheared zone (Fig. 5.C). However, it also showed that multiple small and localised shear bands developed without forming a slip surface. Fig. 7.A shows the displacement of the crown in which no brittle failure can be seen.

\subsection{Test D: Soft Speswhite clay Dyke}

Test $\mathrm{D}$ consisted of a poorly consolidated clayey dyke $\left(\sigma_{v, c}^{\prime}\right.$ $=50 \mathrm{kPa})$ with a high water content $(w=63 \%)$ and an undrained strength $s_{u}$ of $3 \mathrm{kPa}$. The dyke was placed on a stiff silicon subsoil. The dyke underwent large deformation as from the beginning of the test and, at only $4 \mathrm{G}$, a brittle failure took place (Fig. 4.D). The crown displacement, shown in Fig. 7.A, illustrates this premature failure. As the acceleration carried on, the dyke continued its large deformation and a second slide took place. This mechanism car- ried on until the end of the tests by which point the entire dyke was flattened.

\subsection{Test E \& F: Stiff Speswhite clay Dykes}

Tests $\mathrm{E}$ and $\mathrm{F}$ consisted of dykes made out of an overconsolidated Speswhite clay $\left(\sigma_{v, c}^{\prime}=150 \mathrm{kPa}\right)$ and were placed on a stiff and a soft silicon subsoil, respectively. A vacuum in the centrifuge chamber was applied at $50 \mathrm{G}$ for operational reasons.

Test $\mathrm{E}$ consisted of a clayey dyke with an initial water content $w$ of $53 \%$ and an undrained strength $s_{u}$ of $12 \mathrm{kPa}$ which is twice the strength of Test A and three times the strength of Test D. The dyke was placed on a stiff silicon subsoil. The high strength of the dyke and the medium-stiff silicon subsoil limited the deformation up to $100 \mathrm{G}$ at which point large deformations and a brittle failure took place. Fig. 4.E shows the deformation and the slip surface at $100 \mathrm{G}$. Fig. 7.A shows the displacement of the crown in which the brittle failure can be seen. 
Test A: Med-Stiff Speswhite Clay dyke on stiff silicon subsoil $\mathrm{PIV}$ at $41 \mathrm{G}$

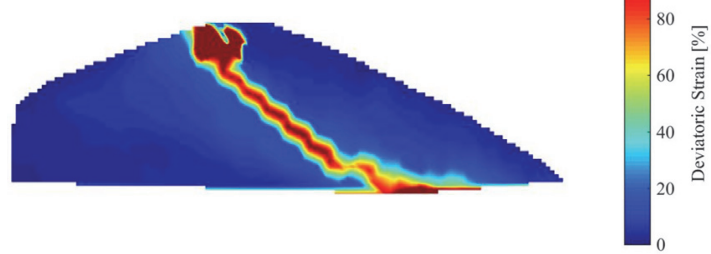

Test B: Med.-Stiff Speswhite Clay dyke on med.-stiff silicon subsoil $\mathrm{PIV}$ at $50 \mathrm{G}$

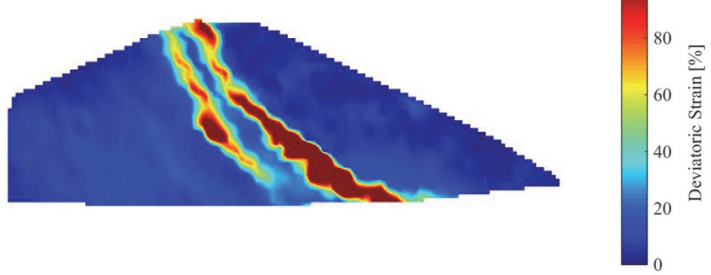

Test C: Med.-Stiff Speswhite Clay dyke on soft silicon subsoil PIV at $100 \mathrm{G}$

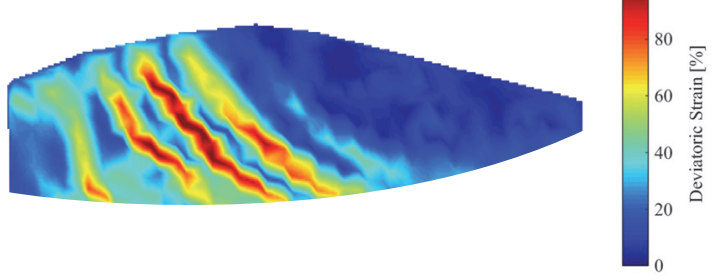

Fig. 5 PIV image of deviatoric strains at failure of the Speswhite clay dykes for tests A, B and C.

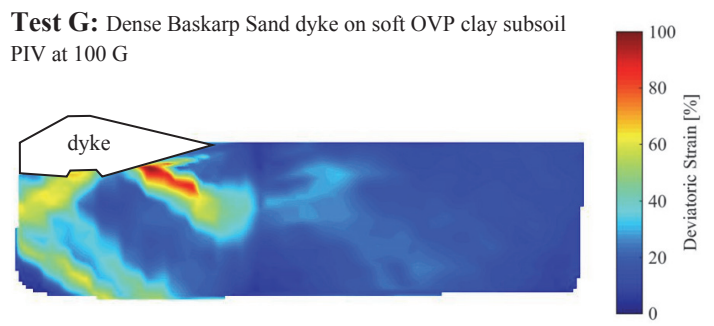

Test H: Dense Baskarp Sand dyke on soft OVP clay subsoil PIV at $100 \mathrm{G}$

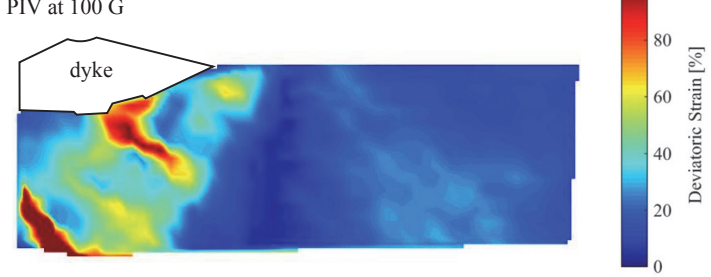

Fig. 6 PIV image of deviatoric strains at $100 \mathrm{G}$ of the natrual (OVP) clay subsoil for tests $\mathrm{G}$ and $\mathrm{H}$.
Test F consisted of a clayey dyke with an initial water content $w$ of $52 \%$ and the undrained shear strength $s_{u}$ was $10 \mathrm{kPa}$. The dyke was placed on a soft silicon subsoil. As the gravity increased, the soft silicon subsoil subsided inducing some deformation in the dyke. However, no brittle failure was observed during the test. Fig. 4.F shows the final deformation of the dyke and its subsoil at $100 \mathrm{G}$. Fig. 7.A shows the displacement of the crown and shows that, despite the dyke being significantly stronger than for Test $\mathrm{C}$, the deformation is very similar, albeit slightly smaller.

\subsection{Test G to I: Dense Baskarp Sand Dykes}

Tests G to I consisted of dykes made out of Baskarp sand with an initial relative density $I_{D}$ of $90 \%$. The dykes in Tests $\mathrm{G}$ and $\mathrm{H}$ were placed on a natural and soft OVP clay subsoil and were duplicates. Test I consisted of the same dyke but placed on a soft silicon subsoil.

Tests $\mathrm{G}$ and $\mathrm{H}$ investigated the behaviour of a natural soft clay subsoil which had an initial water content $w$ of $149 \%$ and an undrained strength $s_{u}$ of $7 \mathrm{kPa}$. The results show that, during the increase of gravity, the water present in the dyke was drained out leaving most of the dyke in a partially saturated state. The drainage of the dyke was apparent for sandy dykes because of its high permeability. The behaviour of the clayey subsoil underwent continuous irreversible deformations with the development of shear bands which propagated into the dyke. These sheared zones developed were different for Test $\mathrm{G}$ and $\mathrm{H}$ and are believed to be related to the presence of discontinuities which favour the development of shear bands. Fig. 4.G and 4.H show the final deformation of both tests. The crown displacements (Fig. 7.B) shows that the displacement of both tests are similar until the localised failures occur at around $50 \mathrm{G}$. Fig. 6 shows the PIV analyses of the natural and soft OVP clay subsoil in which the shear bands are visible.

Test I consisted of a sandy dyke on a soft silicon subsoil. The results of the test show that no slip surface developed in the dyke. However, the large deformation of the subsoil induced the development of rotated shear bands forming a knee-joint type of failure which allowed the dyke deformed with the subsoil. These shear bands are visible in Figure 4.I. 
Fig. 7.B shows the displacement of the crown in which no brittle failure can be seen.

\section{Discussion of the Experimental Results}

The results of the centrifuge tests show that the four dykes resting on a medium-stiff or a stiff subsoil (Test A, B, D and E) developed slip surfaces and part of the dyke slid. The five other dykes resting on a soft subsoil (Test C, F, G, H and I) deformed excessively without the development of any slip surface. The displacements of the crown of the dyke were monitored (Fig. 7) and highlights these two failure mechanisms. These displacements were caused by the deformation of both the dyke and the subsoil. The results show that the rate of displacement of the crown was governed by the deformation of the subsoil. They also show that the development of a slip surface for dykes on medium-stiff and stiff subsoils (Test A, B, D and E) was controlled by the undrained strength of the dyke.

The PIV analysis (Fig. 5) captured the development of strains in the dykes. It showed that strains localised and formed a slip surface for dykes on medium-stiff and stiff subsoils. It also showed the existence of multiple small intensity shear bands within a large sheared zone for dykes on soft subsoils. No mass movement took place in that test.

It can be argued that Test I (dense sand on soft silicon) underwent multiple localised failures forming a 'knee-joint' rather than a large sheared zones. However, these shear bands covered a large area which can be considered as being failed and no mass movement took place in that test.

The results of the centrifuge tests (Fig. 4) also showed that water seeped out of the sandy dykes (Test G, H and I) and can be explained by the high permeability of the sand. Therefore, the sandy dykes were in a partially saturated state and for which the mechanical properties were enhanced. No water seeped out of the clayey dykes, because of its low permeability, and remained fully saturated during the test.

\section{MPM Simulations of the Centrifuge Tests}

The centrifuge tests presented in this paper have been modelled with a Material Point Method (MPM) (Sulsky et al.,
1994, 1995) code called Anura 3D (www.anura3d.com). It is a continuum-based method dedicated for large deforma- 355 tion problems. The ability of MPM to model large deforma- 356 tion mass movements is discussed in Soga et al. (2016). The MPM code was made available for this study by the MPM Research Community. The concept of MPM is to discretise the continuum body into material points. These points are sometimes referred to as 'particles' but, unlike the name suggests, they represent a volume of continuum solid rather than an individual particle of soil. The material points hold all the information required for the computation. The mass is specific to the material point and is conserved throughout the entire simulation. The material points move in a background grid which is purely chosen for computational reasons. The use of a background grid reduces the computational costs with regards to other meshless methods such as SPH and facilitates the definition of the boundary conditions (Bandara, 2013). Its proximity to finite elements allows it to inherit many of its developments such as the constitutive models as well as some of its shortcomings such as some grid dependency. A detailed description of the MPM formulation, used in this study, can be found in Beuth et al. (2011) and Jassim et al. (2013).

The dykes in the experimental tests were saturated during construction. As the centrifuge model was accelerated, water seeped out. This was very apparent for the sandy dykes, which had a high permeability, but not for the clayey dykes, which had a low permeability. Therefore, the sandy dykes were in a partially saturated state. Additionally, a vacuum was created in the air chamber. Ideally, these tests should be simulated using the 3-phase MPM formulation presented in Yerro et al. (2015) with which it is possible to model matric suction and air vacuums. However, solving the governing equations for the three phases is computationally expensive. Therefore, a classical 1-phase approach was adopted in which the sand was modelled as drained, because of its high permeability, and the clay as undrained, because of its low permeability.

Drained conditions imply that the excess pore water pressure is dissipated instantaneously. Therefore, the formulation of MPM can be restricted to a single phase. The effective stress increments $\dot{\sigma}^{\prime}$ are obtained from the strain incre- 

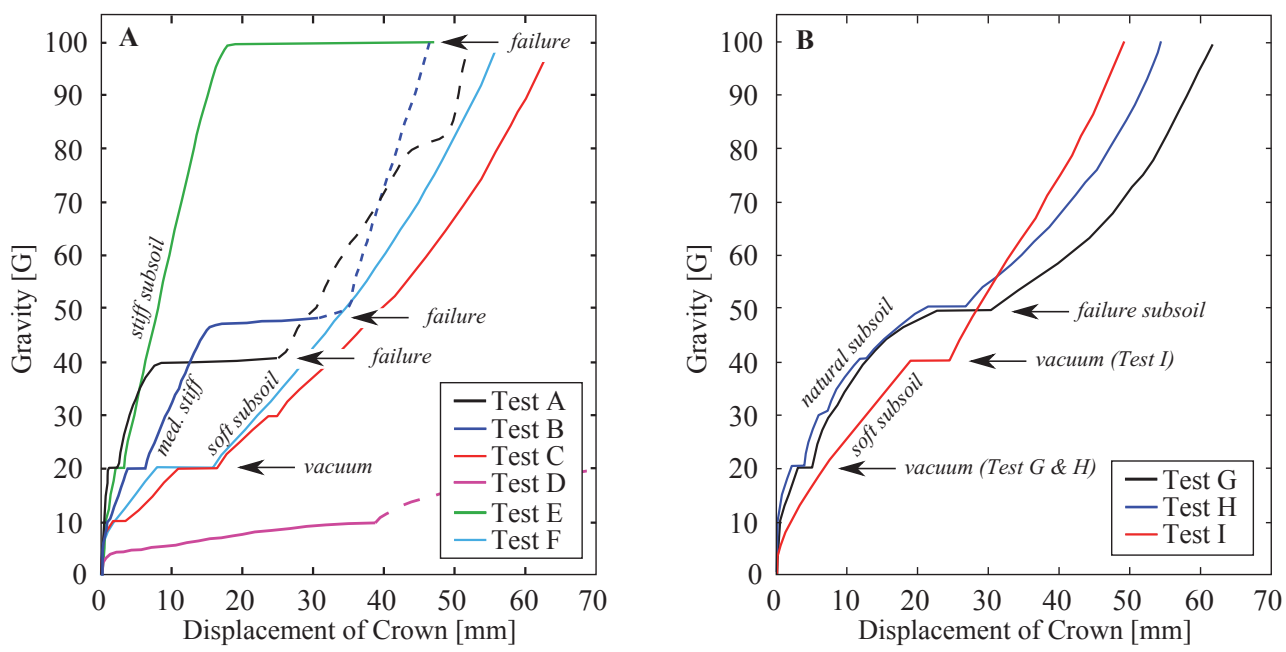

Fig. 7 Displacement of the crown for (A) clayey dykes and (B) sandy dykes.

${ }_{418} \quad \frac{K_{w}}{n}=\frac{3\left(v_{u}-v\right)}{\left(1-2 v_{u}\right)(1+v)} \cdot K$ model (Eq. 1).

$$
\dot{\boldsymbol{\sigma}}^{\prime}=\mathbf{D} \cdot \dot{\boldsymbol{\varepsilon}}
$$
the water (Eq. 2).

$\dot{p}_{e x c}=\frac{K_{w}}{n} \dot{\varepsilon}_{v o l}$ issues. ments $\dot{\boldsymbol{\varepsilon}}$ and the stiffness matrix $\mathbf{D}$ given by the constitutive

Undrained conditions imply that the pore water is maintained within the material. The acceleration of the water coincides with the acceleration of the soil and the formulation of MPM can also be reduced to a single-phase. It implicitly assumes that the soil remains saturated throughout the entire simulation. In this study, the effective stress approach has been adopted and the effective soil parameters are used. The excess pore water pressures were estimated by considering the strain compatibility condition between the soil and

where $\dot{p}_{\text {exc }}$ is the excess pore water pressure increment, $K_{w}$ is the bulk stiffness of the water, $n$ is the soil porosity and $\dot{\varepsilon}_{v o l}$ the volumetric strain rate.

The bulk modulus of the water was estimated by considering the elastic parameters of the soil (Eq. 3). The true bulk modulus of the water cannot be taken into account as the incompressible nature of water would lead to computational

where $K_{w}$ the bulk modulus of the water, $K$ the bulk modulus of the soil, $v_{u}$ is the undrained Poisson ratio of the soil and is assumed to be $0.49, v$ the Poisson ratio of the soil.

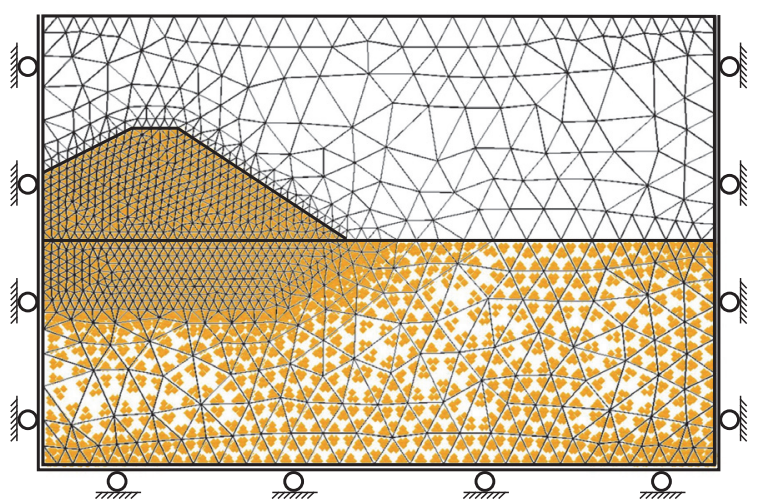

Fig. 8 Schematic description of the MPM model of the centrifuge tests.

5.1 Modelling the centrifuge tests

The MPM model of the centrifuge tests is shown in Fig.

8. The space was meshed with unstructured tetrahedral elements with four material points per cell. Boundary conditions were set in order to avoid any material points leaving the grid. No other numerical features such as dashpots or friction algorithm were used.

The MPM simulations were run as dynamic explicit which 429 allowed to capture the fast development of the slip surfaces. However, explicit codes are computationally expensive and only short duration simulations are possible. Therefore, the loading up to a $100 \mathrm{G}$ was carried out in a 100 seconds. The influence of the fast loading was investigated by running Test I (sandy dyke on soft silicon subsoil) once as dy- 

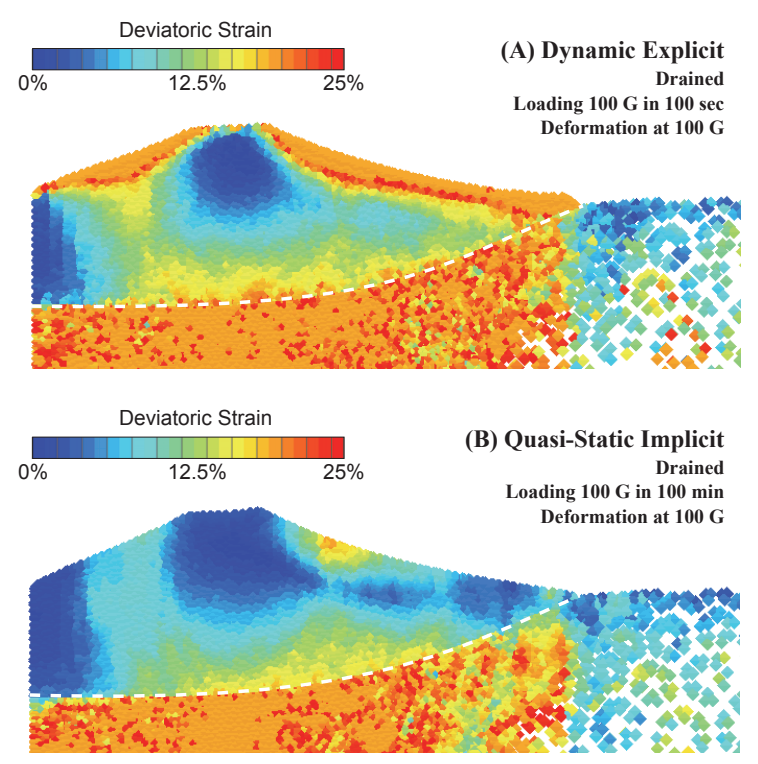

Fig. 9 Dynamic explicit (top) and quasi-static implicit (bottom) MPM simulations of Test I. Material points which have been sheared in excess of $25 \%$ deviatoric strain are mapped in orange.

namic explicit in a 100 seconds and once as quasi-static implicit in a 100 minutes. Fig. 9 shows the results of both simulations which are very similar despite the dynamic explicit simulation predicts some shearing at around the surface of dyke. This is due to the rapid loading and the low stresses at these shallow depths. Furthermore, numerical oscillations can occur with the standard MPM formulation and are caused by material points crossing element boundaries. These oscillation can be mitigated, in some cases, by using more advanced interpolation schemes such as the Generalised Interpolation Material Point Method (Bardenhagen and Kober, 2004) or the Convected Particle Domain Interpolation Method (Sadeghirad et al., 2011).

\subsection{Modelling Undrained Clay}

It is known that the undrained strength $s_{u}$ of soil on the 'wet' side of the critical state line (CSL) is lower than its drained strength, due to its contractive behaviour during shearing, but the undrained strength $s_{u}$ of soil on the 'dry' side of the CSL is larger than its drained strength, due to its dilative nature during shearing. Fig. 10 illustrates the undrained effective stress path in triaxial compression tests of real soil and the idealised stress paths of simple constitutive models

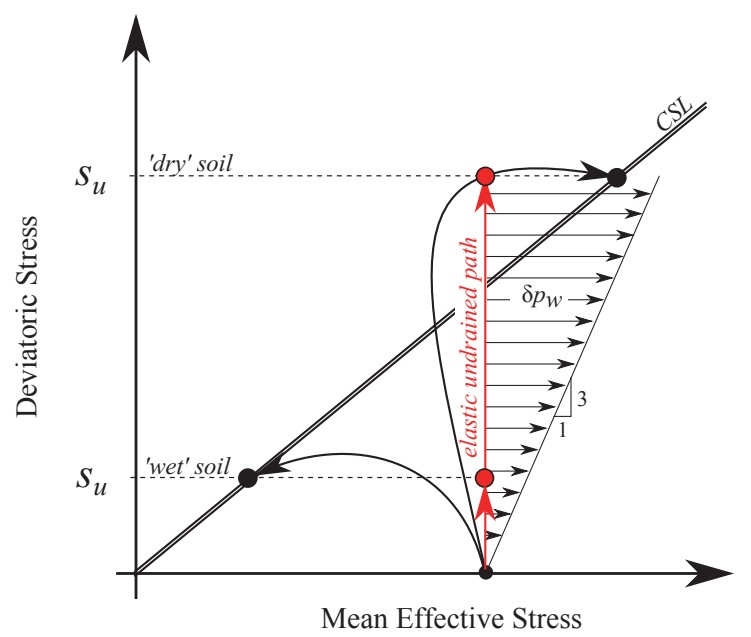

Fig. 10 Undrained stress paths of real soil and modelling paths with simple elastic-plastic failure criteria in triaxial compression tests.

(i.e. Tresca, Mohr-Coulomb). The isotropic elastic hardening phase implies that the deviatoric stress increases with no change in the mean effective stress until failure occurs.

The undrained peak strength $s_{u}$ was estimated for each test using a pocket penetrometer. However, it is also possible to estimate the undrained strength with a state index called the liquidity index (Eq. 4).

$I_{L}=\frac{w-w_{P}}{w_{L}-w_{P}}$

where $I_{L}$ is the liquidity index, $w$ the water content, $w_{P}$ the plastic limit and $w_{L}$ the liquid limit.

Vardanega and Haigh (2014) reviewed the use of such an index to predict the undrained strength of clay and suggested Eq. 5. The measured and estimated values of the undrained strength were consistent with one another and are summarised in Table 2.

$s_{u}=1.7 \cdot 35^{\left(1-I_{L}\right)} \quad 0.2<I_{L}<1.1$

The undrained strength can be used with a Tresca model 474 (Eq. 6) as suggested by Leroueil et al. (1990). Bjerrum (1972) 475 suggested correcting the estimated or measured undrained 476 strength with an empirical factor $\mu$ was found to be $0.9 \quad 477$ for Speswhite clay. The model parameters use for the MPM 478 simulations are summarized in Table 3.

$\tau_{f}=\mu \cdot s_{u}$

where $\tau_{f}$ is the shear strength, $\mu$ the empirical correction ${ }_{481}$ factor and $s_{u}$ the measured undrained strength.

6

477

87


Table 2 Measured and estimated undrained strength of Speswhite clay.

\begin{tabular}{|c|c|c|c|c|}
\hline Test & $w$ & $I_{L}$ & $s_{u}^{\text {meas. }}$ & $s_{u}^{\text {est. }}$ \\
\hline \hline $\mathrm{A}$ & $56 \%$ & $58 \%$ & $6 \mathrm{kPa}$ & $7 \mathrm{kPa}$ \\
\hline $\mathrm{B}$ & $55 \%$ & $55 \%$ & $8 \mathrm{kPa}$ & $8 \mathrm{kPa}$ \\
\hline $\mathrm{C}$ & $55 \%$ & $55 \%$ & $7 \mathrm{kPa}$ & $8 \mathrm{kPa}$ \\
\hline $\mathrm{D}$ & $63 \%$ & $81 \%$ & $3 \mathrm{kPa}$ & $3 \mathrm{kPa}$ \\
\hline $\mathrm{E}$ & $53 \%$ & $48 \%$ & $12 \mathrm{kPa}$ & $11 \mathrm{kPa}$ \\
\hline $\mathrm{F}$ & $52 \%$ & $45 \%$ & $10 \mathrm{kPa}$ & $12 \mathrm{kPa}$ \\
\hline
\end{tabular}

where $s_{u}^{\text {meas. }}$ is the measured undrained strength with the pocket penetrometer and $s_{u}^{e s t}$. the estimated undrained strength (Eq. 5.)

\subsection{Modelling Drained Sand}

Stress paths of dry soil are well known and the effective stresses are equal to the total stresses. As the centrifuge model is accelerated, the stress increases until failure occurs. The sand was modelled with an elastic-plastic strain-softening Mohr-Coulomb model which allowed softening to take place with accumulated plastic deviatoric strain $E_{d}^{p}$. The necessity to use a softening model for large deformation simulations has been discussed in Fern and Soga (2016). The yield function $F$ and the potential function $G$ are expressed respectively in Eq. 7 and 8. The reduction of the model parameters are expressed in Eq. 9 to 11.

$F=q-\left(\frac{c^{\prime}}{\tan \varphi^{\prime}}+p^{\prime}\right) \frac{\sin \varphi^{\prime}}{\cos \theta+\frac{\sin \theta \sin \varphi^{\prime}}{\sqrt{3}}}$

$G=q-\left(a_{p p}+p^{\prime}\right) \frac{\sin \psi}{\cos \theta+\frac{\sin \theta \sin \psi}{\sqrt{3}}}$

where $F$ is the yield function, $c^{\prime}$ the effective cohesion, $\varphi^{\prime}$ the effective friction angle, $\theta$ the Lode angle, $p^{\prime}$ the mean effective stress , $q$ the deviatoric stress, $G$ the potential function and $a_{p p}$ the distance to the apex.

$\frac{\partial \varphi^{\prime}}{\partial E_{d}^{p}}=-\beta\left(\varphi_{\text {peak }}^{\prime}-\varphi_{r e s}^{\prime}\right) \cdot \exp \left(-\beta \cdot E_{d}^{p}\right)$

$\frac{\partial c^{\prime}}{\partial E_{d}^{p}}=-\beta\left(c_{\text {peak }}^{\prime}-c_{r e s}^{\prime}\right) \cdot \exp \left(-\beta \cdot E_{d}^{p}\right)$

$\frac{\partial \psi}{\partial E_{d}^{p}}=-\beta\left(\psi_{\text {max }}-\psi_{\text {res }}\right) \cdot \exp \left(-\beta \cdot E_{d}^{p}\right)$

where $\beta$ is the shape coefficient which controls the rate of softening and the subscripts res, peak and max correspond to the residual state, peak state and maximum value.
Table 3 Model parameters for MPM simulations.

\begin{tabular}{|c|c|c|c|}
\hline & SW Clay & B Sand & OVP Clay \\
\hline Model & Tresca & MCSS & MCSS \\
\hline \hline$E$ & $10 \mathrm{MPa}^{*}$ & $15 \mathrm{MPa}$ & $6 \mathrm{MPa}$ \\
\hline$v$ & 0.2 & 0.2 & 0.2 \\
\hline \hline$\varphi_{\text {peak }}^{\prime}$ & - & $47^{\circ}$ & $15^{\circ}$ \\
\hline$\varphi_{c s}^{\prime}$ & - & $32^{\circ}$ & $10^{\circ}$ \\
\hline$\psi_{\text {max }}$ & - & $19^{\circ}$ & $0^{\circ}$ \\
\hline$\psi_{c s}$ & - & $0^{\circ}$ & $0^{\circ}$ \\
\hline$c_{\text {max }}^{\prime}$ & $0.9 \cdot s_{u}$ & $0 \mathrm{kPa}$ & $0.9 \cdot s_{u}$ \\
\hline$c_{c s}^{\prime}$ & - & $0 \mathrm{kPa}$ & $1 \mathrm{kPa}$ \\
\hline$\beta$ & - & 500 & 100 \\
\hline
\end{tabular}

* $E=1 \mathrm{MPa}$ for Test D (soft Speswhite clay) where SW for Speswhite, OVP for Oostvaardersplassen, B stands for Baskarp and MCSS for Mohr-Coulomb Strain Softening. The value of the undrained strength $s_{u}$ are given in Table 2.

The peak friction angle $\varphi_{\text {peak }}$ and the maximum dilatancy angle $\psi_{\max }$ were estimated using a state index called the relative dilatancy index $I_{R}$ (Bolton, 1986) which is based on the stress-dilatancy theory (Taylor, 1948; Rowe, 1962) and expressed in Eq. 12 to 15.

$\varphi_{\text {peak }}^{\prime}=\varphi_{c s}^{\prime}+0.8 \cdot \psi_{\max }$

$\psi_{\max }=\alpha \cdot I_{R}$

$I_{R}=I_{D} \cdot \ln \left(\frac{Q}{p^{\prime}}\right)-1$

$I_{D}=\frac{e_{\max }-e}{e_{\max }-e_{\min }}$

where $I_{R}$ is the relative dilatancy index, $I_{D}$ the relative density, $Q$ the crushing pressure which is specific to the mineralogy of the sand and is equal to $10 \mathrm{MPa}$ for silica sand and $\alpha$ the dilatancy coefficient which is equal to 6.25 in plane strain conditions (Bolton, 1986).

The relative density $I_{D}$ was $90 \%$ and, assuming a mean effective stress $p^{\prime}$ of $100 \mathrm{kPa}$, the relative dilatancy index $I_{R}$ was found to be 3.14. Hence, the maximum dilatancy angle $\psi_{\max }$ and peak friction angle $\varphi_{\text {peak }}^{\prime}$ were $19^{\circ}$ and $47^{\circ}$. The critical state friction angle $\varphi_{c s}^{\prime}$ of Baskarp sand is $32^{\circ}$ and the critical state dilatancy angle $\psi_{c s}$ is by definition equal to zero (Roscoe et al., 1958). The sand was assumed to be cohesionless and the shape factor $\beta$ to be 500 . The shape function $\beta$ only controls the softening rate and does not influence either the peak strength (small deformation) nor the critical 
state strength (large deformation). It was chosen based on previous work (i.e. Soga et al., 2016). However, it is meshdependent and, hence, will change from one simulations to another. The Poisson ratio $v$ was assumed to be 0.2 which is a typical value for silica sands (Jefferies and Been, 2006) and the Young's modulus $E$ estimated at $10 \mathrm{MPa}$. The model parameters use for the MPM simulations are summarized in Table 3.

\subsection{Modelling Silicon}

The silicon blocks were prepared in order to achieve a specific stiffness in order to impose a deformation to the dyke and the stresses within the silicon blocks were not of interests. However, silicon has a complex viscous behaviour. The short duration of the tests mitigated this effect and the blocks were considered to be elastic and incompressible. The Poisson ratio $v$ was chosen to be 0.49 and the elastic moduli $E$ to match the experimental values $(E=114,565$ and 1,377 $\mathrm{kPa})$.

\section{Results of the Numerical Simulations}

The results of the MPM simulations are summarised in Fig. 11. The snapshots were taken at the on-set of failure. The colour mapping represents the deviatoric strain ( $0 \%$ blue to $50 \%$ red). The experimental profile of the deformed dyke at the on-set of failure is sketch with a black line and the experimental slip surfaces and shear bands with dashed red lines.

\subsection{Test A-C: Medium-Stiff Speswhite Clay Dykes}

Test A consisted of a medium-stiff Speswhite clay dyke resting on a stiff silicon subsoil. The results of the simulation showed little deformation until $30 \mathrm{G}$ at which point a sheared zone developed from the toe of the dyke and along the base. It then propagated from the centre of the base diagonally towards the crest of the dyke. Its intensity increased substantially from 30 to $40 \mathrm{G}$ by which point a slip surface was formed. Fig 11.A shows the deviatoric strain at this point. The mobilised mass slid in a viscous manner rather than a blocky one as observed in the experiment. This can be explained by the assumption that the entire dyke is fully saturated and incompressible as well as some limitations of a simple constitutive model (i.e. homogeneity and isotropy).

Test B consisted of the same dyke as for Test A (mediumstiff Speswhite clay) but resting on a medium-stiff silicon subsoil. The results of the simulation show little deformation until $50 \mathrm{G}$ at which point a sheared zone developed from the toe of the dyke to the crest in the same way it did for the simulation of Test A. However, the development of the slip surface was faster in this case. Fig. 11.B shows the deviatoric strain at this point. The slip surface in the experiment took place at $48 \mathrm{G}$ and was shortly followed by the appearance of two shear bands. The difference between the numerical predictions and the experimental results can be explained by the way the pore pressures were calculated and their influence of the effective stresses.

Test $\mathrm{C}$ consisted of the same dyke as for Test A and B (medium-stiff Speswhite clay) but resting on a soft silicon subsoil. The results of the simulation show that the silicon subsoil deformed with increasing centrifugal acceleration. The dyke was, in turn, deformed and the distribution of strains was very diffuse. As the model approached $100 \mathrm{G}$, the deformation in the dyke concentrated at the base of the dyke. Fig. 11.C shows the deviatoric strains at this point. The failure mechanism was noticeably different from the simulations of Test A and B and very consistent with the experimental results of Test $\mathrm{C}$ for which no slip surface took place.

\subsection{Test D: Soft Speswhite Clay Dykes}

Test D consisted of a soft Speswhite clay dyke resting on a soft silicon subsoil. The results of the simulations show little deformation up to $20 \mathrm{G}$. Then, a large area of the dyke underwent large deformation and, by $28 \mathrm{G}$, multiple shear bands developed with a large portion of the dyke sliding. This can be seen in Fig. 11.D. The failure mechanism predicted by the numerical simulation resembled the one observed in the experimental test in the sense that a large portion of the dyke was mobilised and in which a brittle failure took place. However, the failure of the dyke took place at $28 \mathrm{G}$ in the numerical simulation whereas it took place at 


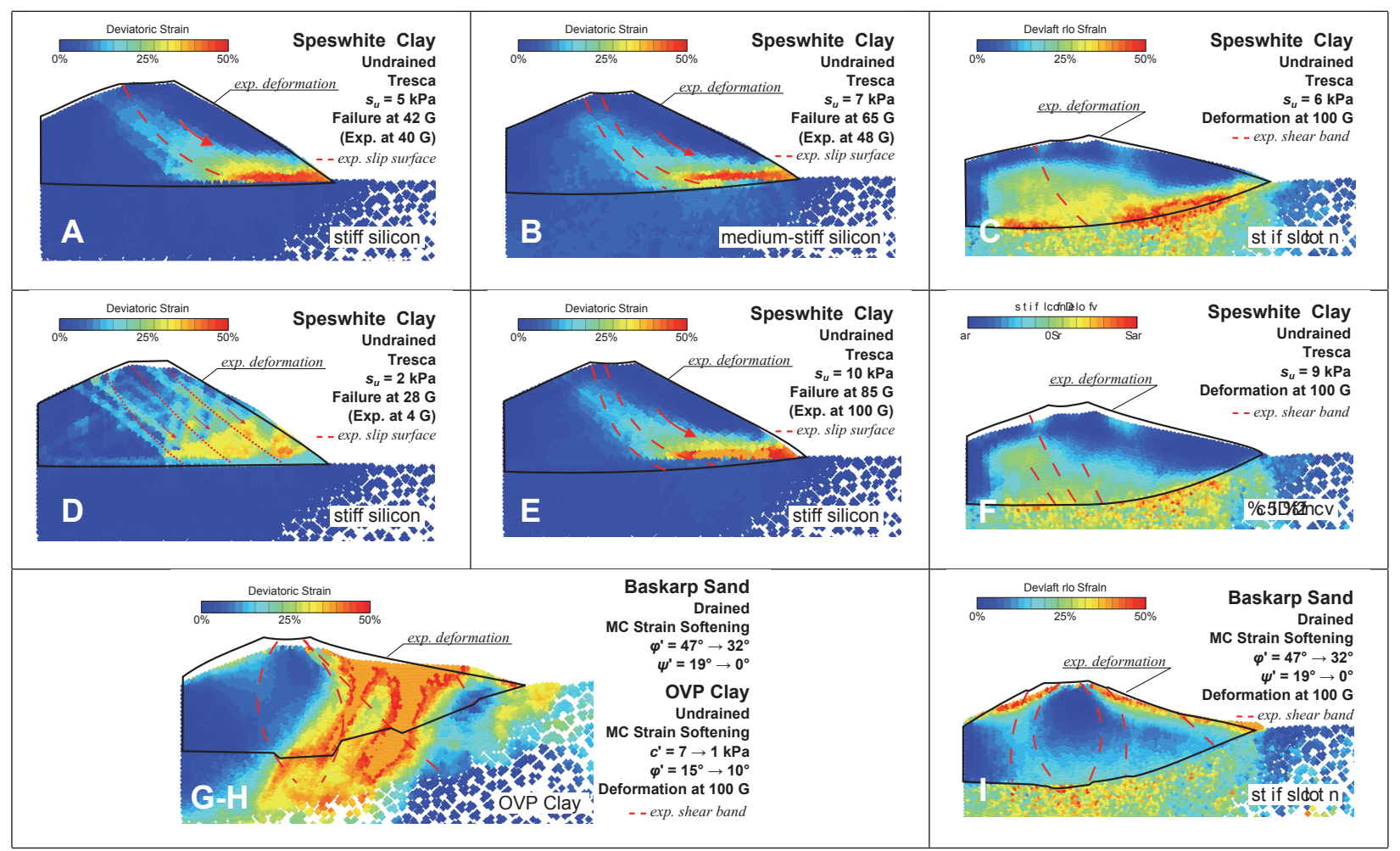

Fig. 11 Dynamic explicit MPM simulations of centrifuge tests with Mohr-Coulomb Strain Softening. The colour mapping corresponds to the deviatoric strain ( $0 \%$ blue to $50 \%$ red). Material points which have been sheared in excess of $50 \%$ deviatoric strain are mapped in orange.

$4 \mathrm{G}$ in the experimental test. This can be explained by the modelling assumptions. The dyke undergoes solely elastic deformation with little deformation and pore pressure before failing at the prescribed strength.

\subsection{Test E \& F: Stiff Speswhite Clay Dykes}

Test E consisted of a stiff Speswhite clay dyke resting on a stiff silicon subsoil. The results of the simulation showed that very little deformation took place prior to $60 \mathrm{G}$. Larger deformations then took place and, at $85 \mathrm{G}$, a slip surface was formed in a similar way it did for Test A and B. This can be seen in Fig. 11.E. The predicted failure took place at a lower G-level than in the experiment and can be explained by the fully saturated assumption. However, the shape of the predicted slip surface is identical to Test A and B whereas the experimental evidence shows a deeper seated failure. This can be potentially explained by the anisotropy of the clay inferred by the vertical consolidation in a stiff tub and limitations of the simple constitutive models. However, further investigation of the induced fabric is needed.
Test F consisted of the same dyke as for Test E (stiff Speswhite clay) but this time resting on a soft silicon subsoil. The results of the simulation showed that the dyke was continuously sheared with the centrifugal acceleration. Fig. 11.F shows the final configuration of the dyke in which a large sheared zone can be seen. The strain distribution differs slightly from Test $\mathrm{C}$ in the sense that the large sheared zones was mostly in the centre left part of the dyke. The results of the MPM simulation were consistent with the experimental observations which showed large areas of the dyke being deformed excessively without any slip surface developing.

\subsection{Test I to H: Dense Baskarp Sand Dykes}

Test I consisted of a dense Baskarp sand dyke resting on a soft silicon subsoil. The results of the simulation showed that, as for Test $\mathrm{C}$ and $\mathrm{F}$, the deformation of the soft silicon subsoil induced deformations in the dyke. As the model was loaded, the dyke deformed with a knee-joint mechanism as shown in Fig 11.I. Note that the clayey dykes on soft sub- 

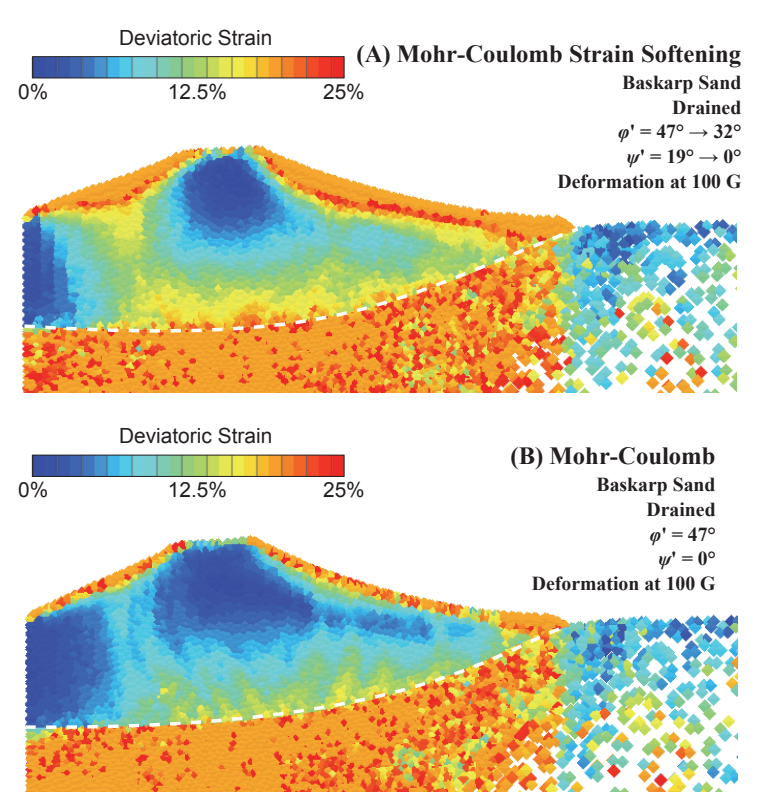

Fig. 12 MPM simulation of Test I (A) with softening and (B) without softening. soil (Test C and F) also show some features of a 'knee-joint' mechanism. The initiation and development of shear bands were strongly related to the inhomogeneities and the softening behaviour of dense sand. Fig. 12 shows the same results as in Fig 11.I but with a smaller mapping scale and compares the results with and without softening behaviours. It was observed during the simulations that the inclusion of softening facilitated the formation of shear bands and resulted in larger areas of largely deformed soil.

Test $\mathrm{G}$ and $\mathrm{H}$ were duplicates of the same tests. They consisted in the same dyke as for Test I (dense Baskarp sand, $I_{D}=90 \%$ ) but were resting on a natural and soft OVP clay subsoil. Both materials were modelled with the MohrCoulomb Strain Softening model and, therefore, plasticity was permitted in the subsoil. The results of the MPM simulations (Fig. 11.G-H) show the rapid development of two shear bands at around $10 \mathrm{G}$ which propagated through the dyke and into the subsoil. This was not the case in Test I which had a soft elastic silicon subsoil. The two shear bands divided the dyke into three distinct areas which were then able to move up and down independently. As from 30 $\mathrm{G}$, a large area of subsoil had yielded and fast developing large deformations were taking place. Both the appearance soil were observed in the experiments. However, the location of shear bands and the sudden large deformation of the sub- and orientation of the shear band differed between the MPM simulation and the two experimental tests. It is known that the on-set of shear bands is caused by inhomogeneities in the soil. The experimental test used a natural clay as a subsoil and, therefore, had some natural imperfection which led to a different pattern of shear banding.

\section{Discussion of the Numerical Results}

The MPM simulations were able to capture the slip surfaces of the four dykes resting on medium-stiff and stiff subsoils (Test A, B, D and E) and the excessive deformation of the five dykes resting on soft subsoils (Test C, F, G-H and I). The simulation showed that a reduction in stiffness of the subsoil for a given dyke led to a delay in the development of the slip surface (Test A and B) and that an increase of the undrained strength $s_{u}$ of dykes resting on stiff subsoils delayed the formation of the slip surface (Test A, E and D). This shows that the stiffness of the subsoil contributes to the stability of the dyke as much as the strength properties.

The MPM simulations were also able to capture the excessive deformation of dykes resting on soft subsoils in which no slip surface developed. It was able to predict the large sheared zones for the clayey dykes (Test $\mathrm{C}$ and $\mathrm{F}$ ) and the 'knee-joint' mechanism for the sandy dykes (Test G-H and I).

The inclusion of plasticity in the subsoil (Test G-H) increased the complexity of its mechanical behaviour and, hence, ${ }_{696}$ the dyke-subsoil interaction. The MPM simulation confirmed ${ }_{697}$ the ability of shear bands to propagate through the different materials and highlighted the influence of the subsoil on the failure of the dyke.

\section{Conclusion}

Nine centrifuge tests were carried out to investigate the different failure mechanisms of dykes resting on soft to stiff subsoils. The centrifuge models were subjected to an increase in gravity up to $100 \mathrm{G}$ in 100 minutes. Six dykes were made out of Speswhite clay and three out of Baskarp sand. Three subsoils were made out of silicon in order to mimic a soft to stiff elastic subsoil and one subsoil was made out 
of a natural and soft OVP clay. The results of the experiments showed that the stiffness of the subsoil strongly influenced the failure mechanism. Only four out of nine tests out resulted in the formation of a slip surface and mass movement. The five others resulted in excessive deformation. The numerical modelling confirmed the existence of these two failure mechanism.

1. Slip surface. This type of failure occurred in dykes resting on medium-stiff to stiff subsoils (Test A, B, D and E) which underwent little deformation but developed a slip surface. The strength of the dyke influenced the G-level at which the brittle failure took place.

2. Excessive deformation. This type of failure occurred with dykes on soft subsoils (Test C, F, G-H and I) which subsided significantly with increasing G-levels and in which no slip surface developed. The clayey dykes showed an asymmetrical distribution of deviatoric strains whilst the sandy dyke exhibited a symmetrical pattern in the form of a 'knee-joint' with the development of shear bands. The sandy dykes on the natural and soft OVP clay subsoil showed some similarities but with additional complexity due to the yielding of the subsoil.

The numerical simulations replicated both types of failure using simple constitutive models for which the model parameters were estimated from state indices. The numerical simulations showed that the deformed configuration of the dyke and its subsoil, which involved large deformation, played an important role in the failure mechanism. The Material Point Method showed to be a valuable tool in assessing the stability of the dykes.

A step has been made in understanding the behaviour of dykes involving soft soils and its numerical modelling. However, the relevance of these tests in reproducing real dykes can be discussed because of the loading procedure (increasing gravity), the use of homogeneous soils prepared in laboratory and the use of elastic subsoils. Many dykes in the Netherlands were built in the Middle Age and the deformations of the subsoil have already taken place. Furthermore, many secondary dykes were built with locally available materials, including rubble, which differs substantially from the materials used in this study. Nevertheless, the simplicity in execution and understanding of this study offers some insight on the interaction between the dyke and its subsoil.

Acknowledgements The authors acknowledge the Dutch Ministry of Public Works (Rijkswaterstaat-WVL) and the HHNK Water Authority for commissioning and financing the centrifuge tests. They would also like to thank the European Unions Seventh Framework Programme for research, technological development and demonstration under grant agreement no PIAP-GA-2012-324522 and the Swiss National Science Foundation under grant agreement P1SKP2 158621 for additional funding for the analysis of the data and the numerical modelling.

\section{References}

T. Abdoun, V. Bennett, and R. Dobry. Real-Time Monitoring of Full-Scale Levee Testing. In 7th International Conference on Physical Modelling in Geotechnics, pages 1171-1176, Zurich, 2010. ISBN 9780415592888.

F.C. Andersen, J.A. Battjes, D.E. Daniel, B. Edge, W. Easpey, R.B. Gilbert, T.L. Jackson, D. Kennedy, D.S. Mileti, J.K. Mitchell, P. Nicholson, C.A. Pugh, G. Tamaro, R. Traver, J. Buhrman, C.V. Dinges, J.E. Durrant, J. Howel, and L.H. Roth. The New Orleans Hurrican Protection system : What Went Wrong and Why. Technical report, ASCE, Reston, VA, 2007.

S. Bandara. Material Point Method to Simulate Large Deformation Problems in Fluid-Saturated Granular Medium. $\mathrm{PhD}$ thesis, University of Cambridge, 2013.

S.G. Bardenhagen and E.M. Kober. The generalized interpolation material point method. 5(6):477-496, 2004. 762

L. Beuth, Z. Wieckowski, and P.A. Vermeer. Solution of quasi-static large-strain problems by the material point method. International Journal for Numerical and Analytical Methods in Geomechanics, 35(13):1451-1465, 2011. doi: 10.1002/nag.965.

L. Bjerrum. Embankments on Soft Ground. In Performance of Earth-Supported Structures, pages 1-54. Purdue University, 1972.

M.D. Bolton. The Strength and Dilatancy of Sands. Géotechnique, 36(1):65-78, 1986.

E.J. Fern and K. Soga. The role of constitutive models in MPM simulations of granular column collapses (published online). Acta Geotechnica, feb 2016. ISSN 18611125. doi: 10.1007/s11440-016-0436-x.

0


A.G.I. Hjortneas-Pedersen and H. Broers. SE-704441/1 Material Properties of Oostvaardersplassen Clay. Technical report, Delft Geotechnics, 1993.

I. Jassim, D. Stolle, and P. Vermeer. Two-phase dynamic analysis by material point method. International Journal for Numerical and Analytical Methods in Geomechanics, 37(15):2502-2522, 2013. doi: 10.1002/nag.2146.

M. Jefferies and K. Been. Soil Liquefaction A Critical State Approach. Taylor \& Francis, London, 2006. ISBN 9780419161707.

A. Koelewijn and M.A. Van. Stability Analysis for Embankments Prone to Uplift Induced Failure. In G.N. Pande and S. Pietruszczak, editors, 8th International Sympossium on Numerical Models in Geomechanics, pages 561564, Rome, jan 2002. Taylor \& Francis. doi: 10.1201/ 9781439833797-c83.

A.R. Koelewijn, G.J.C.M. Hoffmans, and M.A. Van. Lessons Learned from a Full-Scale Dyke Failure Test. In 5th International Conference on Case Histories in Geotechnical Engineering, 2004.

S. Leroueil, J.-P. Magnan, and F. Tavenas. Embankments on Soft Clay. Ellis Horwood, Chichester, 1990.

K.H. Roscoe, A.N. Schofield, and C.P. Wroth. On The Yielding of Soils. Géotechnique, 8(1):22-53, jan 1958. ISSN 0016-8505. doi: 10.1680/geot.1958.8.1.22.

P.W. Rowe. The Stress-Dilatancy Relation for Static Equilibrium of an Assembly of Particles in Contact. In Proceedings of the Royal Society A: Mathematical, Physical and Engineering Sciences, volume 269, pages 500-527. The Royal Society, 1962.

A. Sadeghirad, R.M. Brannon, and J. Burghardt. A convected particle domain interpolation technique to extend applicability of the material point method for problems involving massive deformations. International Journal for Numerical Methods in Engineering, 86(12):14351456, 2011. doi: 10.1002/nme.3110.

R.B. Seed. Letter 'Re: New Orleans, Hurrican Katrina, and the Soul of the Profession' to ASCE president Dr W.F. Macuson, 2007.

G.L. Sills, N.D. Vroman, R.E. Wahl, and N.T. Schwanz. Overview of New Orleans Levee Failures: Lessons Learned and Their Impact on National Levee Design and
Assessment. Journal of Geotechnical and Geoenvironmental Engineering, 134(5):556-565, 2008. ISSN 10900241. doi: 10.1061/(ASCE)1090-0241(2008)134:5(556).

K. Soga, E.E. Alonso, A. Yerro, K. Kumar, and S. Bandara. Trends in large-deformation analysis of landslide mass movements with particular emphasis on the material point method. Géotechnique, 66(3):248-273, mar 2016. ISSN 0016-8505. doi: 10.1680/jgeot.15.LM.005.

D.L. Sulsky, Z. Chen, and H.L. Schreyer. A Particle Method for History-Dependent Materials. Computer Methods in Applied Mechanics and Engineering, 118:179-196, 1994.

D.L. Sulsky, S.-J. Zhou, and H. Schreyer. Application of a Particle-in-Cell Method to Solid Mechanics. Computer Physics Communications, 87:236-252, 1995.

D.W. Taylor. Fundamentals of Soil Mechanics. Wiley, New York, 1948.

M.A. Van, C. Zwanenburg, A.R. Koelewijn, and H. Van Lottum. Evaluation of Full Scale Levee Stability Tests at Booneschans and Corresponding Centrifuge Tests. Proceedings of the 17th International Conference on Soil Mechanics and Geotechnical Engineering: The Academia and Practice of Geotechnical Engineering, 3:2048-2051, 2009. doi: 10.3233/978-1-60750-031-5-2048.

S. Van Baars. The Horizontal Failure Mechanism of the Wilnis Peat Dyke. Géotechnique, 55(4):319-323, 2005. ISSN 0016-8505. doi: 10.1680/geot.2005.55.4.319.

P.J. Vardanega and S.K. Haigh. The Undrained Strength Liquidity Index Relationship. Canadian Geotechnical Journal, 51(9):1073-1086, sep 2014. ISSN 0008-3674. doi: 10.1139/cgj-2013-0169.

B.F. Vink. Some Aspects of the Engineering Practice Regarding Peat in Small Polders. In E. den Haan, R. Termaat, and T.B. Edil, editors, Advances in Understanding and Modelling Mechanical Behaviour of Peat, pages 389492, Rotterdam, 1994.

D.J. White, W.A. Take, and M.D. Bolton. Soil Deformation Measurement Using Particle Image Velocimetry (PIV) and Photogrammetry. Géotechnique, 53(7):619631, 2003. ISSN 0016-8505. doi: 10.1680/geot.2003.53. 7.619.

A. Yerro, E.E. Alonso, and N.M. Pinyol. The Material Point Method for Unsaturated Soils. Géotechnique, 65(3):201- 
217, 2015. ISSN 0016-8505. doi: 10.1680/geot.14.P.163.

876 C. Zwanenburg, E.J. Den Haan, G.A.M. Kruse, and A.R.

877 Koelewijn. Failure of a Trial Embankment on Peat in 878 Booneschans, the Netherlands. Géotechnique, 62(6):479490, 2012. ISSN 0016-8505. doi: 10.1680/geot.9.P.094. 